analysis reinforced the arguments of previous speakers for operating through informal groups. Much more, he thought, could be done through the guided discussion group. Special emphasis should be placed on means for assessing the success or failure of the methods used by advisory services. $\mathrm{He}$ advocated co-operative research in Great Britain similar to that which he had cited from the United States. He suggested that greater attention should be paid to the attitudes of farmers towards new procedures, and very special attention given to their "uninhibited reactions to our present advisory services".

Contributions to the discussion from the floor were, very appropriately, in the form of such uninhibited reactions of the practical farmers themselves. They reinforced what Dr. Harper and others had said regarding the importance of understanding the needs of those for whom advisory services are provided. It seemed clearly to emerge that scientific advice administered neat is apt to be ineffective. The scientific advisory officer needs to be not only a man of science but also something of a management consultant, competent to advise the farmer in costing the procedures suggested, and able to assist him in adapting general principles to the special circumstances and the particular economy of his farm. This conclusion was in close accordance with an opinion expressed in a conference on farm management organized by the British Institute of Management earlier in the year. A combined scientific and management advisory service is what is most needed. Such a service is of especial importance for the small farmers who comprise the vast majority of those for whom these services are provided.

There would appear, too, to be a substantial body of opinion which favours more detailed and intensive advisory services to a smaller number of farms in preference to a wider service spread more thinly. If it is indeed true that farmers learn more readily from practical demonstrations of successful farming than from the spoken or written word, a well-distributed selection of farms serviced in detail might be more effective than more diffused methods. It is agreed, however, that, whether focused or diffused, advice must be followed up by inquiries whether the advice has been acted on: If not, why not; and if so, with what effect? Follow-up provides the 'knowledge of results', the 'feed back', upon which success depends ; and to make this a routine procedure may be more useful and less expensive than the organization of special attitude and opinion surveys of consumers needs and reactions.

It is of interest to note that, although the symposium was especially concerned with advisory services to the farmer, the policies and principles discussed were of universal application. Regulations continue to multiply, but in all modern civilized societies there is a greater proportionate increase in the use of methods based on advice and persuasion. Advisory services are developing for agriculture, for building and most of the manufacturing industries, and the ordinary citizen has an immense variety of advisory services concerned with his health, his education, his vocational needs, his civil rights and responsibilities. In all these advisory services there is a need for better understanding of the sources of friction and resistance in the channels of communication from the laboratory or the field station to those who have to turn the results of scientific research to practical account.
This was the first joint meeting of the Agriculture and Psychology Sections in the history of the British Association; but with the continued expansion of research and advisory services, it may well be the precursor of many symposia on the psychological aspects of the technique of applying the methods and results of science to human affairs.

\section{BIOLOGICALLY SIGNIFICANT MACROMOLECULES}

A MEETING of Section B (Chemistry) of the British Association took place in Belfast on September 9 before a packed audience under the chairmanship of Prof. M. Stacey (professor of organic and biological chemistry in the University of Birmingham), the subject being "Biologically Significant Macromolecules".

Prof. Stacey spoke on "Polysaccharides of Medical Importance". In the normal functioning of the animal body the synthesis of macromolecules and their subsequent breakdown is of obvious importance. Continuous biological polymerization and depolymerization are essential in growth processes and provide a fascinating study especially in the polysaccharide field. It is perhaps not surprising that the medical applications of complex carbohydrates are becoming of increasing importance.

A good deal is now known regarding the so-called immunologically specific bacterial polysaccharides, especially in the Salmonella and Pneumococcus groups. In the pneumococcus the polysaccharides occur mainly on the surface of the bacterial cell as a capsule from which they may pass into solution in the growth medium of the organism. When they penetrate into the animal body, they stimulate the production of immune proteins, and in vitro in very high dilution they give rise to a specific precipitate on reaction with homologous immune serum. There are more than fifty of these specific polysaccharides, each possessing a different chemical structure, though their physical properties may be similar. A special characteristic is that many of them possess hexosamines and hexuronic acids, in addition to hexoses, as constituent building-units. During recent years, Prof. M. Heidelberger and his colleagues in the United States have shown that the pneumococcus polysaccharides free from protein will immunize human beings against infection, and a mixture of polysaccharides may be used as a prophylactic vaccine against pneumonia. The protection will last up to twelve months, and in large communities the incidence of many types of pneumonia can be lessened.

Vaccines against typhoid, dysentery and cholera, etc., mainly owe their immunizing properties to the presence of a complex carbohydrate residue which contains glucosamine and galactose and which is conjugated to phospholipids and amino-acids.

Seven distinct polysaccharides have been obtained from the mycobacterium which causes tuberculosis in humans, and their specific serological reactions are being studied. When freed from protein, they do not appear to give rise to any immunity. When polysaccharides having molecular weights of the order of a million are degraded by acid or by enzymes, they can often be injected into animals without setting up any immunity in the host. They may, 
however, cause skin reactions in sensitive individuals, and some forms of allergy can be traced to distinct chemical structures or even groupings, though protein constituents or nucleoproteins are more likely to be incriminated in such cases.

The bacterial polysaccharide dextran has been degraded by a variety of means, and a fraction having a molecular weight not greater than a hundred thousand has been used successfully as a blood plasma substitute. It is being used extensively, particularly in Britain and Sweden, in conjunction with natural plasma against shock, burns and loss of blood. The polysaccharide is composed entirely of glucose units, and it is completely metabolized in the body within a few days.

Another valuable dextran product is the sulphate made from a fraction having a molecular weight of about twenty thousand. This is essentially non-toxic, and it prevents the coagulation of blood and is likely to become valuable in post-operative work and in thrombosis. It has an action like heparin, the natural anticoagulant. Blood-group substances present in the red cells and tissues of individuals of groups $\mathrm{A}$, $\mathrm{B}$ or $\mathrm{O}$, ete., are mainly of a polysaccharide nature. Their study by chemical means will give valuable information on inheritance characters.

Body 'building' constituents, such as bone, cartilage, tendons and joint fluids, are polysaccharides containing hexuronic acids, amino-sugars, sulphate and acetyl residues. They can be depolymerized by enzymes such as hyaluronidase, lysozyme, etc., and the state of polymerization appears to be important in certain rheumatic conditions. The enzymes may be under the control of cortisone or the adrenocorticotropic hormone, and it is of great importance to make structural studies in the group.

The biosynthesis of one macromolecule may depress that of another type in its immediate vicinity. There is some evidence that certain bacterial polysaccharides will suppress the formation of the nucleoproteins in some tumours, and efforts have been made for some years by Dr. M. J. Shear and his colleagues in the United States to apply this in the attempted cure of some forms of cancer. In a somewhat similar way microbial and other polysaccharides may cause the slowing-down or may suppress the growth of viruses such as the influenza virus. Physical factors come into play, and efforts are being made to investigate virus multiplication and inhibition along these lines.

Dr. B. E. Conway (Chester Beatty Institute, London) then gave an account of the "Physical Chemistry of Deoxyribonucleic Acid". The probable importance of deoxyribonucleic acid conjugated with basic proteins to form the chromosomal nucleoproteins and in the process of cell division was stressed, and the action of ionizing radiations and radiomimetic substances such as the 'nitrogen mustards' on dividing cells was briefly indicated. Attention was directed to the great amount of information to be gained by studying the effects of these agents on isolated deoxypentosenucleic acid. However, prior to investigations of this type it is necessary to have some information concerning the physical condition of nucleic acid solutions. Dr. Conway briefly reviewed experimental studies by various workers in which the ultracentrifugal, diffusion, viscosity, streaming birefringence and light scattering behaviours were observed. These experiments led to a picture of nucleic acid solutions as consisting of a dispersion of highly elongated, fairly rigid particles, between which there is considerable electrostatic and or van der Waals' interaction. The marked effect of simple uni-univalent salts on the viscosity of the nucleic acid, together with the observation of Signer and Schwander that the orientation of the nucleic acid particles in streaming birefringence experiments is independent of sodium chloride concentration in the solution, emphasizes the apparent importance of electrostatic interactions between particles in nucleic acid and its solutions. In addition to these effects with simple salts, the addition of hydrogen-bond competing agents (or 'denaturing agents'), such as urea or phenol, to the nucleic acid solutions produces an irreversible effect in which it appears that the nucleic acid, although unchanged in molecular weight by these agents, becomes more compact by a loosening of intramolecular hydrogen bonds which appear to stiffen the extended rod-like structure.

Both radiomimetic agents, for example, the nitrogen mustard

$$
\mathrm{CH}_{3}-\mathrm{N}\left\langle\begin{array}{l}
\mathrm{CH}_{2} \cdot \mathrm{CH}_{2} \mathrm{Cl} \\
\mathrm{CH}_{2} \mathrm{CH}_{2} \mathrm{Cl}
\end{array},\right.
$$

and $\mathrm{X}$-rays have an apparent depolymerizing effect on nucleic acid. However, the chemical effects of these two types of agents are very different, and only the physical changes of viscosity and molecular weight are similar. In the case of the nitrogen mustard, direct alkylation of the nucleic acid alters the molecule to a more compact form. At the same time and afterwards, further fission of the nucleic acid chain occurs giving fragments of lower molecular weight. The chemistry of these processes was briefly discussed. In the case of the action of X-rays on aqueous solutions of nucleic acid, the reactive agents are the hydroxyl, hydrogen and hydroxylonium free radicals, the latter being formed only in oxygenated solutions. The chemical action of hydroxyl radicals on nucleic acid and simpler analogues was described. There is a wide variety of reactions which can be brought about by these hydroxyl radicals interacting with nucleic acid. The effects of $\mathrm{X}$-irradiation of nucleic acid in oxygen are of particular interest, for here degradation continues long after cessation of the irradiation. The importance of hydrogen peroxide formed during the irradiation under these conditions was discussed, and the possible relation of the increased radiosensitivity of organisms in the presence of-oxygen was pointed out. Dr. Conway's talk was beautifully illustrated by slides showing stages of cell division.

In the final paper, Dr. G. A. Gilbert (University of Birmingham) spoke of the work in the Birmingham laboratories and elsewhere on "Enzymes for Building Natural and Synthetic Starch". He said that natural starch contains two distinct kinds of polymer-a long straight-chain polymer (two hundred units) termed 'amylose', and a highly ramified polymer termed 'amylopectin'. Amylose tends to come out of solution in hot water in the form of a granular powder (retrogradation), whereas amylopectin forms a thick gel. Tough fibres resembling cellulose can be made from amylose. It gives a blue-coloured complex with iodine, the molecules and ions of which may fit inside a helix-type of chain structure. Amylopectin gives a reddish colour with iodine, and the amylose content of a starch may be measured by the 'blue value' of the iodine complex measured spectrophotometrically. Separation of amylose from a starch paste may be 
achieved by the addition of a variety of reagents, including thymol, paraffins, aluminium phosphate, etc.

Amylose may be synthesized by the action of an enzyme (Hanes's phosphorylase or $P$-enzyme) acting upon glucose-1-phosphate under appropriate conditions. The phosphorylase may be extracted readily from potato juice and obtained in a highly purified form. The synthesis using purified materials will not begin until a 'primer' consisting of several glucose units with the starch-type pattern is added. The synthesis starts from the non-reducing chain ends, and the glucose units are joined by $1: 4 \alpha$-glycosidic linkages. Amylose may be converted into amylopectin by a second 'branching' enzyme termed $Q$-enzyme which has been obtained in Birmingham in a crystalline condition. The branching may involve 1 : 6-linkages which are now termed 'cross' linkages. The synthesis of the starch components by these enzymes, alone and in admixture in varying proportions, gives a valuable means of studying an important biological synthesis. The depolymerization of starch components can be studied by means of the 'amylase' enzymes, which have some commercial importance. There is a good deal of overlap in the mode of action of starch-synthesizing and -depolymerizing enzymes obtained from microbial, protozoal, plant and animal tissues.

The meeting concluded with a lively discussion.

\section{OBITUARIES}

\section{Prof. C. B. Fawcett}

Prof. C. B. Fawcett, who held the chair of geography at University College, London, for twentyone years until his retirement in 1949, died on September 21 at the age of sixty-nine.

A graduate of University College, Nottingham, he later studied under Herbertson at Oxford before becoming lecturer in geography at University College, Southampton, in 1914. He moved in 1919 to the University of Leeds, where he was in charge of the young Department of Geography until he was appointed in 1928 to succeed Prof. L. W. Lyde in London.

Fawcett was a leading member of the group of pupils of Mackinder and Herbertson who pioneered the modern development of honours schools of geography in British universities, and he was for many years prominent in the counsels of the Geographical Association, Section E (Geography) of the British Association, and the Institute of British Geographers, of which he was one of the founders and an early president.

A faith in the essential reasonableness of his fellow men, as well as his own rationalism, permeated all his work, and were revealed, for example, in his interest in the development of an auxiliary world language and calendar reform. They found particular expression in "The Bases of a World Commonwealth", published in the darkest period of the Second World War. His emphasis upon the unity of the Atlantic community combined with his personal qualities to make him a ready and welcome visitor to New England. Having already been visiting professor at Clark University, Worcester, Mass., in 1931 and again in 1947, he returned there for two years after retiring from the chair at University College, London.
It is perhaps too soon to attempt an assessment of his contribution to the development of geographical thought; but the significance of his early work, "The Provinces of England" (1919), in the history of the regional concept is already evident. That it should have been specifically written to point a reasonable basis for devolution of government and reform of administrative areas was typical of his essentially practical outlook. Geography claimed his absorbing interest not for its own sake, but also as a social science which in its application to social and political problems could increase the sum of human happiness. To the studies of population problems and political geography, which increasingly engaged his attention, he brought an insistence upon appreciating the realities of hard facts. His own command of facts was an unfailing source of wonder to his students, who will remember the encyclopædic knowledge on all manner of topics which illumined or diverted his lectures, as they will his unfailing kindliness and outstanding fairmindedness.

A. E. SMainifs

\section{Prof. Aikitu Tanakadate}

Friends and acquaintances of Prof. Aikitu Tanakadate will learn with regret of his death on May 21 in Tokyo, after a long and active life of ninety-five years.

He was born in 1856 at Fukuoka town in the present Iwate Prefecture, Japan. Entering the University of Tokyo in 1878, he studied physics under J. A. Ewing and T. C. Mendenhall, and afterwards under C. G Knott, who were at that time visiting teachers of the University. His interest was particularly directed towards geophysical phenomena, and soon after graduation he started gravimetric and magnetic surveys over Japan, which had not been explored scientifically by that time. "A Magnetic Survey of Japan", which was written by him with admirable thoroughness and completeness and was published in 1904 , is universally known as a monumental work of this kind. In 1888 he went to Glasgow, where he studied physics as a pupil of Sir William Thomson (Lord Kelvin). He returned to Japan in 1891 and in that year was appointed a professor in the University of Tokyo, a post which he held until 1917.

Prof. Tanakadate was the oldest member of the Japan Academy of Science, an emeritus professor of the University of Tokyo, the first recipient of the Order of Cultural Merit, sometime vice-president of the National Research Council of Japan, and a member of the House of Peers. He also held important positions in many learned societies. For more than seventy years of his career as a scientist he literally devoted himself to initiating and promoting natural sciences in Japan. His activity covered fields in a wide range of subjects-to mention a few, geodesy, variation of latitude, seismology, terrestrial magnetism and aeronautics. Japan urgently needed such a pioneer as Prof. Tanakadate, particularly towards the end of the nineteenth century, after the Meiji Restoration of 1868, which brought to an end the three hundred years of Shogunate feudalism. His love of science as well as of his native country seems to have been the primary motive which drove him to this honourable duty. This does not mean that he was a man of narrow-sighted nationalism. On the contrary, he is known as a strong advocate of international friendship and co-operation. He travelled abroad no less than twenty-three times and attended 